\title{
STUDY OF HYDROGEN SULFIDE REMOVAL FROM GRUNDWATER
}

\author{
Tudor Lupaşcu, Mihail Ciobanu, Victor Boțan, Taras Gromovoy a \\ Silvea Cibotaru, Oleg Petuhov, Tatiana Mitina \\ Institute of Chemistry of Science of Moldova, Academiei str. 3, MD 2028 Chisinau, Republic of Moldova \\ ${ }^{a}$ O. Chiuco Institute of Surface Chemistry, National Academy of Science of Ukraine, 17, \\ General Naumov Street, Kyiv 03164 Ukraine \\ E-mail: lupascut@gmail.com; Phone: +37322725490
}

\begin{abstract}
The process of the hydrogen sulfide removal from the underground water of the Hancesti town has been investigated. By oxygen bubbling through the water containing hydrogen sulfide, from the Hancesti well tube, sulfur is deposited in the porous structure of studied catalysts, which decreases their catalytic activity. Concomitantly, the process of adsorption / oxidation of hydrogen sulfide to sulfate take place. The kinetic research of the hydrogen sulfide removal from the Hancesti underground water, after its treatment by hydrogen peroxide, proves greater efficiency than in the case of modified carbonic adsorbents. As a result of used treatment, hydrogen sulfide is completely oxidized to sulfates.
\end{abstract}

Keywords: catalysts, hydrogen sulfide, adsorption/oxidation, hydrogen peroxide, sulfur, sulfate

\section{Introduction}

One of the current problems of mankind is supplying quality drinking water to the population. This issue is very important for Moldova, since our country surface water sources are limited and unevenly distributed over the country, and the groundwater $(\sim 50 \%)$ do not meet drinking water quality indices.

Removal of hydrogen sulfide from groundwater containing sulfide concentrations ten times higher than the admissible concentration is a current problem of great importance [1-7].

Groundwater in Moldova contain quantities well above the maximum permissible concentrations of pollutants such as: sulfur ions, fluoride, ammonia, nitrates, nitrites, iron, manganese, strontium, lead, sulfides.

Presence of hydrogen sulfide in groundwater used for public supply causes various diseases of human health. In compliance with the health requirements of international standards for drinking water, concentration should not exceed $0.1 \mathrm{mg} / \mathrm{L}$. In some geographical areas of Moldova concentration exceeds $10 \mathrm{mg} / \mathrm{l}$. Analysis of scientific literature confirms the existence of several groundwater purification technologies to remove hydrogen sulfide. Most commonly used is the method of oxidation of sulfide ions by aeration in the presence of solid supports including activated carbon.

In this paper, as the catalytic support for removing sulfides in groundwater the industrial activated carbon BAU-A was used, intact and modified.

\section{Experimental}

Dissolved in water, hydrogen sulfide is included in a series of chemical reactions [1] as follows:

(1) Dissociation of molecular hydrogen sulfide to form the bisulfide ion

$\mathrm{H}_{2} \mathrm{~S} \leftrightarrow \mathrm{HS}^{-}+\mathrm{H}_{(\mathrm{a})}^{-}$

(2) Dissociation of bisulfide into sulfide ion,

$\mathrm{HS}_{(\mathrm{a})}^{-} \leftrightarrow \mathrm{H}^{+}{ }_{(\mathrm{a})}+\mathrm{S}^{2-}{ }_{(\mathrm{a})}$

(3) Ionization of water itself.

$\mathrm{H}_{2} \mathrm{O} \leftrightarrow \mathrm{H}^{+}{ }_{(\mathrm{a})}+\mathrm{OH}^{-}{ }_{(\mathrm{a})}$

Thus, the total concentration of hydrogen sulfide includes all sulfide species.

$$
\mathrm{t}_{\mathrm{H} 2 \mathrm{~S}}=\mathrm{m}_{\mathrm{H} 2 \mathrm{~S}}+\mathrm{m}_{\mathrm{HS}^{-}}+\mathrm{m}_{\mathrm{S}} 2-
$$

In [1] it is shown that bisulfide ion concentration increases proportionally with increasing $\mathrm{pH}$ in the range 1-8. In accordance with the regulations in force in the Republic of Moldova drinking water $\mathrm{pH}$ is between 6.5 and 9.5. The $\mathrm{pH}$ value of the water from the fountain subject study was 8.7.

The BAU-A activated carbon intact and oxidized was impregnated with following metal ions: $\mathrm{Cu}^{2+}, \mathrm{Fe}^{3+}, \mathrm{Mn}^{2+}$, from individual solutions as well as with $\mathrm{Fe}^{3+}$ and $\mathrm{Cu}^{2+}$ together. The process of impregnating the activated carbon BAU-A consisted in periodical stirring of the adsorbent in the chloride $10 \%$ solution of the respective cation. The ratio between solid and liquid phase is of 1:4. The period of impregnation of the adsorbent is 4 days. Finally the solid phase is separated from the liquid, washed with distilled water until the salts excess is eliminated and dried at a temperature of $110^{\circ} \mathrm{C}$ to constant mass. Geometric surface and structure parameters of activated charcoal thus obtained were determined from adsorption-desorption isotherms of nitrogen measured at 1MP Autosorb instrument. Parameters of porous structure 
were calculated using and the NLDFT (Density Functional Theory Non-Local) method, DR and BET equation [8].In the table 1 is prezented the parameters of the structures and geometric surface of activated carbon BAU-A intact, oxidated, modificated with $\mathrm{Mn}^{2+}$ ions and BAU-A $+\mathrm{Cu}^{2+}$ intact and BAU-A $+\mathrm{Cu}^{2+}+\mathrm{PDW}-$ in the lost simples the process of adsorption/oxidation was efectuated in the dimeneralization water (PDW)..

Table 1

Geometric surface (Ssp $\left.\mathrm{m}^{2} / \mathrm{g}\right)$, micropor volume $\left(\mathrm{V}_{\mathrm{mi}}, \mathrm{cm}^{3} / \mathrm{g}\right)$, adsorption energy $(\mathrm{E} \mathrm{kJ} / \mathrm{mol})$, maximal adsorption volume (Vs, $\left.\mathrm{cm}^{3} / \mathrm{g}\right)$ for samples of activated carbon BAU-A intact, oxidated, modificated with $\mathrm{Mn}^{2+}$ ions and BAU-A+ $\mathrm{Cu}^{2+}$ intact and BAU-A+ $\mathrm{Cu}^{2+}-($ PDW).

\begin{tabular}{|c|c|c|c|c|}
\hline AC sample & $\mathrm{S}_{\mathrm{BET}}, \mathrm{m}^{2} / \mathrm{g}$ & Vs, $\mathbf{c m}^{3} / \mathrm{g}$ & $\begin{array}{c}\text { Vmi, } \mathrm{cm}^{3} / \mathrm{g}, \\
\text { t-method }\end{array}$ & $\begin{array}{c}\text { Ea, kJ/mol } \\
\text { Equation DR }\end{array}$ \\
\hline BAU-A intact & 727,75 & 0,395 & 0,264 & 21,24 \\
\hline $\mathrm{BAU}-\mathrm{A}+\mathrm{Mn}$ & 696,31 & 0,396 & 0,241 & 21,22 \\
\hline BAU-A ox. & 948,72 & 0,541 & 0,323 & 21,23 \\
\hline BAU-Aox. $+\mathrm{Cu}$ & 753,34 & 0,459 & 0,252 & 20,86 \\
\hline BAU-A+Cu ${ }^{2+}$ intact & 1090,7 & 0,560 & 0,405 & 20,72 \\
\hline BAU-A $+\mathbf{C u}^{2+}$ PDW & 780 & 0,354 & 0,294 & 21,29 \\
\hline
\end{tabular}

The data presented in Table 1 show that, after impregnation of intact activated carbon BAU-A with $\mathrm{Cu}^{2+}, \mathrm{Fe}^{3+}$, $\mathrm{Mn}^{2+}$ ions and of the oxidized BAU-A with $\mathrm{Fe}^{3+}+\mathrm{Cu}^{2+}$ structure parameters and geometric surface of obtained samples significantly changed in the impregnation process. The process of adsorption/oxidation was conducted at the semi-pilot installation presented in Figure 1. The reactor volume was of 201, bubbling time - 1 hour, bubbled air pressure - 2 at., the amount of water to be tested - 10 liters, the amount of carbon catalyst - 10g. The initial concentration of hydrogen sulfide in the groundwater of Hancesti was equal to $5.1 \mathrm{mg} / \mathrm{l}$ and that of sulfates $-71.2 \mathrm{mg} / \mathrm{l}$.

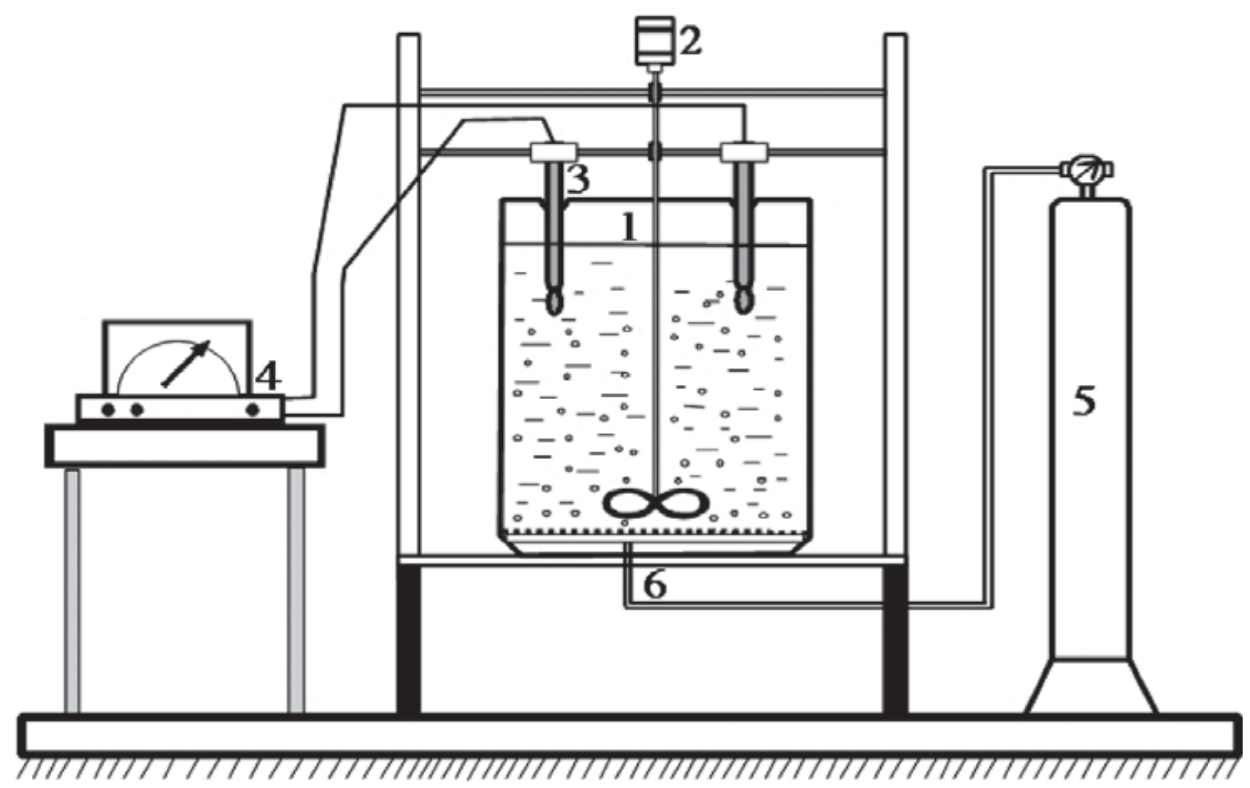

Fig. 1. Scheme of the semi-pilot installation for the study of hydrogen sulfide adsorption-desorption processes, where: 1 - reactor, 2 - stirrer, 3 - electrodes, 4 - pH/mV-meter, 5 - oxygen supply, 6 - membrane allowing the formation of a uniform gas flow in the whole volume.

Adsorption-oxidation processes of sulfide ions were determined by quantitative determinations of their concentrations and the concentration of sulfate ions. Efficiency of the carbon catalysts was established in several cycles of use. Intact and oxidized activated carbons surface chemistry was determined from the analysis of mass spectra measured with temperature-programmed desorption - mass spectrometry (TPD-MS) were performed using a custommade system, the design and detailed explanation of which was presented in [9].( The system was based on an MX7304A mass spectrometer(Sumy, Ukraine), with a mass range of 2-200 Da, electron impact energy of $70 \mathrm{eV}$, and sensitivity of $10^{-8} \mathrm{~g}$. 


\section{Results and discussions}

Analysis of sulfide Ion concentration after completion of each cycle of investigations, using both BAU-A + Mn catalyst and BAU-A $+\mathrm{Cu}$ allowed to conclude that the entire amount of sulfide in groundwater disappears. To elucidate the mechanism of this process was determined the amount of sulfur ions in the initial water and that in the water which underwent oxidation. The results are presented in Table 2.

Table 2

Concentrations of sulfate and ammonia ions per cycles

\begin{tabular}{|c|c|c|c|c|c|}
\hline \multirow{2}{*}{ Ions } & \multicolumn{5}{|c|}{ Determined values } \\
\cline { 2 - 6 } & Cycle 1 & Cycle 2 & Cycle 3 & Cycle 4 & Cycle 5 \\
\hline Sulfate $\left(\mathrm{SO}_{4}{ }^{2-}\right), \mathrm{mg} / \mathrm{dm}^{3}$ & 84,9 & 85,2 & 87,4 & 85,0 & 91,5 \\
\hline Ammonia $\left(\mathrm{NH}_{4}^{+}\right), \mathrm{mg} / \mathrm{dm}^{3}$ & 2,14 & 2,35 & 2,34 & 2,64 & 2,76 \\
\hline
\end{tabular}

The data presented in Table 2 shows an increase in sulfate ions concentration from $71.2 \mathrm{mg} / 1$ to an average of 86.9 $\mathrm{mg} / \mathrm{l}$. This increase is due to the oxidation of sulfur that is found in groundwater according to the reaction: $\mathrm{S}^{2-}+2 \mathrm{O}_{2}=$ $\mathrm{SO}_{4}^{2-}$. Ammonium ions are persistent and not subjected to oxidation process in those conditions.

In order to establish the chemistry and surface phenomena were analyzed mass spectra of initial carbonic catalysts and of those which underwent sulfide oxidation processes.

TPD-mass spectra of samples: BAU-A intact, BAU-Aox $+\mathrm{Cu}^{2+}$; BAU-Aox. $+\mathrm{Cu}^{2+}$ after 5 cycles, BAU-A + $\mathrm{Mn}^{2+}$; BAU-A $+\mathrm{Mn}^{2+}$ after 10 cycles are shown in Figures 2 - 6. TPD-mass spectra represent qualitative information about desorption of compounds with masses of 16 a.m.u.(O), 28 a.m.u.(CO), 32 a.m.u. (S), 44 a.m.u.(CO $)$, 48 a.m.u., 64 a.m.u. effused (formed) as function of temperature. (In the figures below, the lines representing different molecular weights are as follows:

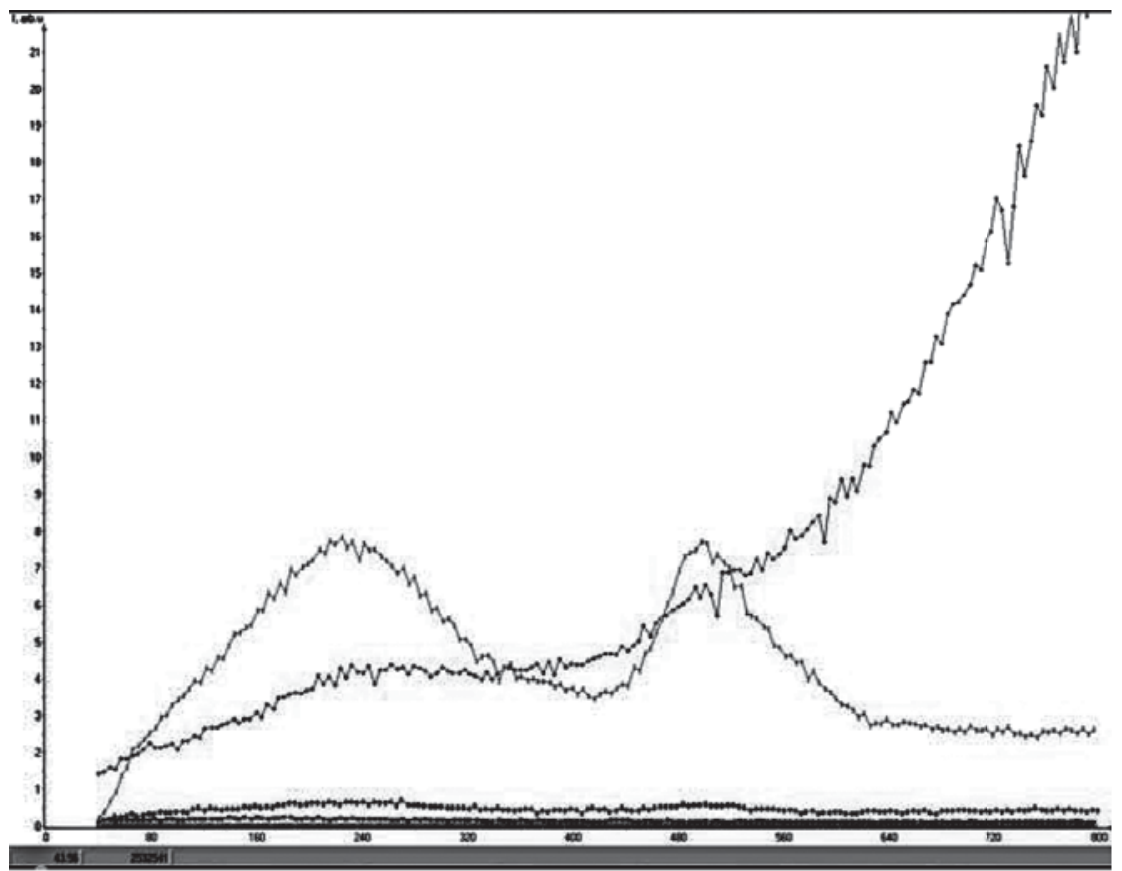

Fig. 2. TPD mass spectrum of volatile products of the intact BAU-A activated carbon sample.

$+16,+28,+32, \quad+44, \quad+48, \quad \rightarrow 64$ 


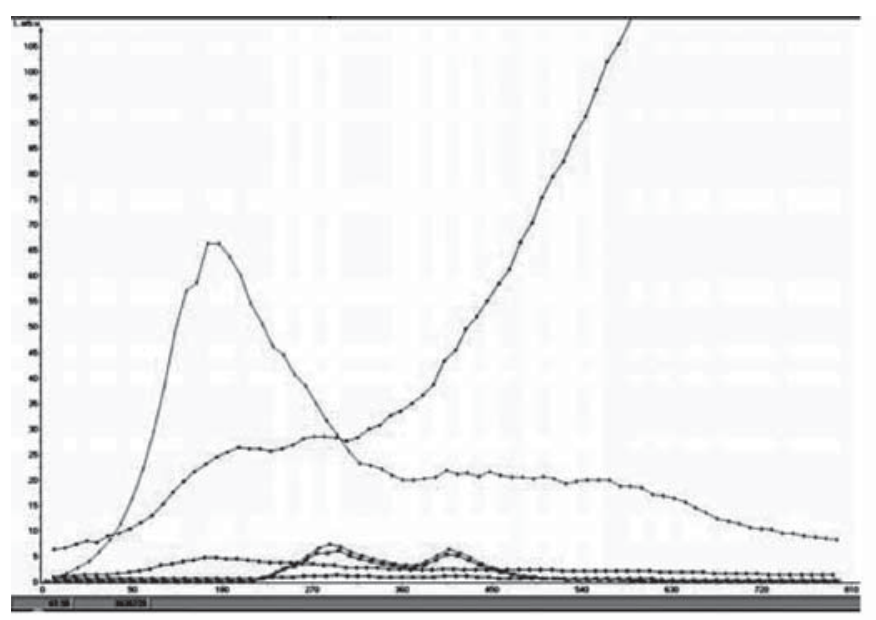

Fig. 3. TPD mass spectrum of volatile products of the BAU-A ox. $+\mathrm{Cu}^{2+}$ activated carbon sample $+16,+28, \quad * 32, \quad \div 44, \quad+48, \quad * 64$

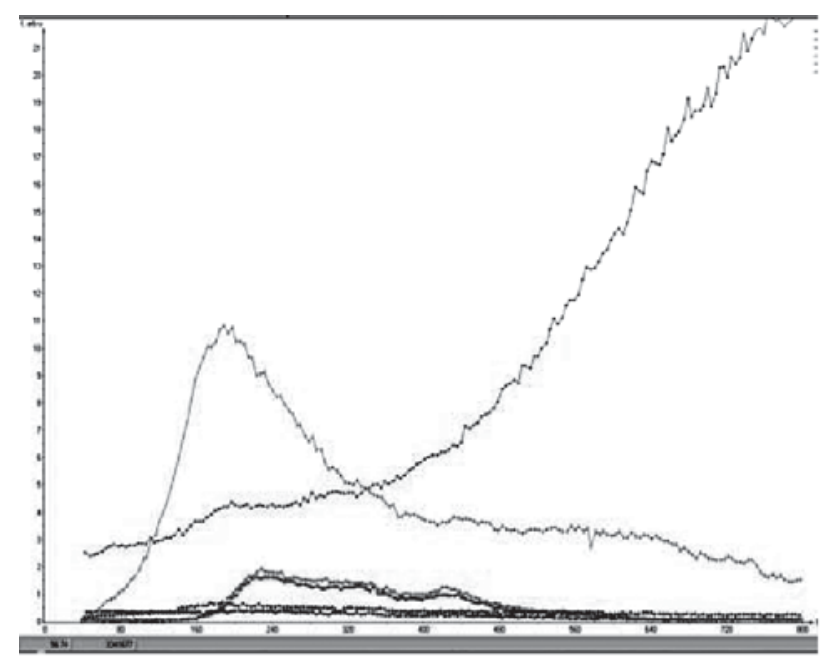

Fig. 4. TPD mass spectrum of volatile products of the BAU-A ox. $+\mathrm{Cu}^{2+}$ activated carbon sample after 5 utilization cycles.

$+16,+28, \quad+32, \quad+44, \quad+48, \quad+64$

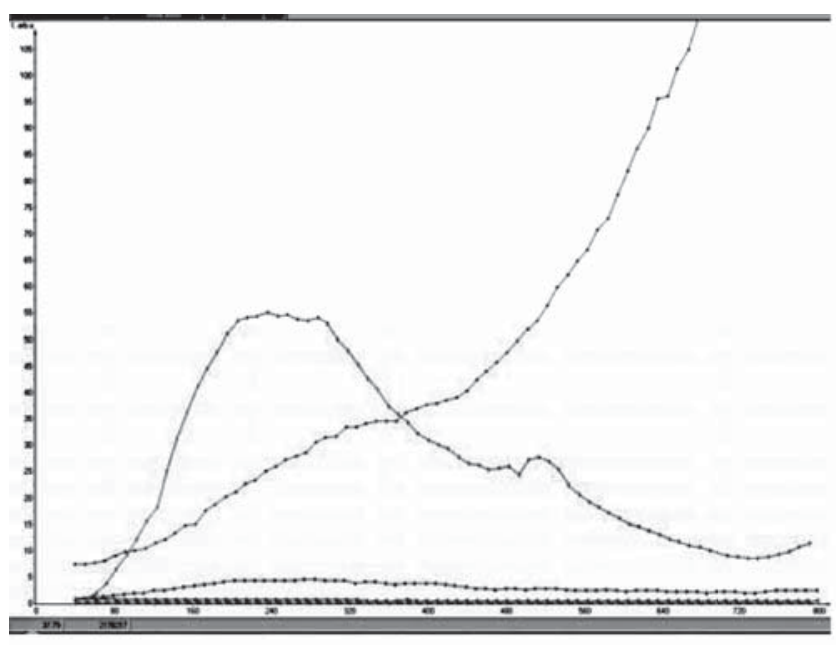

Fig. 5. TPD mass spectrum of volatile products of the BAU-A + $\mathrm{Mn}^{2+}$ activated carbon sample $+16,+28,+32,+44, \quad+48, \quad+64$ 


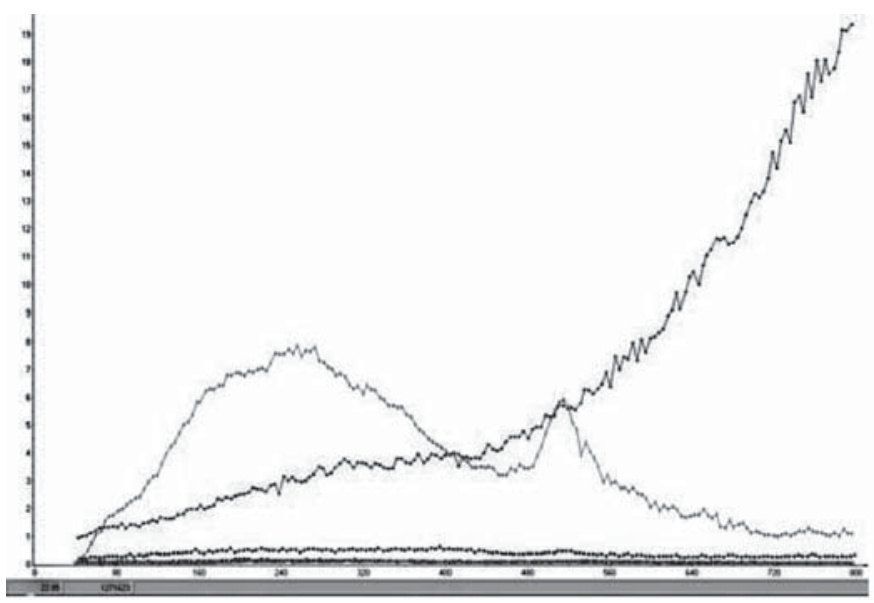

Fig. 6. TPD mass spectrum of volatile products of the BAU-A $+\mathbf{M n}^{2+}$ activated carbon sample after 10 utilization cycles.

$+16,+28, \quad+32, \quad+44, \quad+48, \quad \rightarrow 64$

Analysis of mass spectra allows us to make the following conclusions. TPD-mass spectra of intact and modified adsorbents by their nature can be separated into two groups: mass spectra of intact activated carbon BAU-A (Fig. 2), of the modified carbon adsorbent BAU-A $+\mathrm{Mn}^{2+}$ (Fig. 5) and of the carbon catalyst BAU-A $+\mathrm{Mn}^{2+}$ after 10 cycles of use (Fig. 6). TPD-mass spectra analysis of above mentioned results reveals that heating leads to the removal of carbon dioxide and of carbon monoxide on the surface of these spectra. Be noted that carbon dioxide is eliminated in all three cases at temperatures of about $240^{\circ} \mathrm{C}$ and $520^{\circ} \mathrm{C}$. Carbon monoxide is smoothly eliminated in all cases to the temperature of around $500^{\circ} \mathrm{C}$, followed by an intense elimination of this gas. In the second group of mass spectra are placed the spectra of oxidized active carbon BAU-A $+\mathrm{Cu}^{2+}$ (Fig. 3) and BAU-A ox. $+\mathrm{Cu}^{2+}$ after 5 cycles of use (Fig. 4). Analysis of these two TPD-mass spectra reveals that carbon dioxide is removed from the catalyst surface only at temperatures around $180^{\circ} \mathrm{C}$. Carbon monoxide begins to eliminate from the surface of adsorbents intensely more quickly at a temperature of only $340{ }^{\circ} \mathrm{C}$. In these two spectra is detected the elimination of two compounds with molecular masses of 48 a.m.u. and 64 a.m.u. at temperatures of about $290^{\circ} \mathrm{C}$ and $400^{\circ} \mathrm{C}$ for the catalyst BAU-oxidized $+\mathrm{Cu}^{2+}$. For catalyst BAU-A ox. $+\mathrm{Cu}^{2+}$ after 5 cycles of use, these emissions is recorded at temperatures of about $240{ }^{\circ} \mathrm{C}$ and about $430^{\circ} \mathrm{C}$. Different behaviors of carbon adsorbents during heating may be explained by the fact that during oxidation of the activated carbon on its surface are formed different functional groups which are removed at heat interventions. It should be noted that the mass spectrum line, corresponding to compounds with molecular mass 32 a.m.u. and 16 a.m.u. is parallel to the Ox axis at a value of approximately zero for all 5 substances investigated. From these data we conclude that in the oxidation of hydrogen sulfide colloidal sulfur is not formed, which is very important for the practical realization of technologies of hydrogen sulfide elimination from groundwater by means of catalytic oxidation.

Fig .7 shows the dependence of specific surface of oxidized activated carbon BAU-A $+\mathrm{Cu}^{2+}$ per cycles, which shows the decrease of Ssp ( BET surface area is recommended by IUPAC) value with increasing number of cycles. Experimental points deviate somewhat from the strictly linear dependence, this can be explained by the need for continuity interference in the process to take coal samples in order to determine their specific surface. For the same reason we find deficiencies in Ssp values of oxidized intact activated carbon BAU-A $+\mathrm{Cu}^{2+}($ Table 1$)$ and Ssp of oxidized activated carbon BAU-A $+\mathrm{Cu}^{2+}$ after 1 cycle.

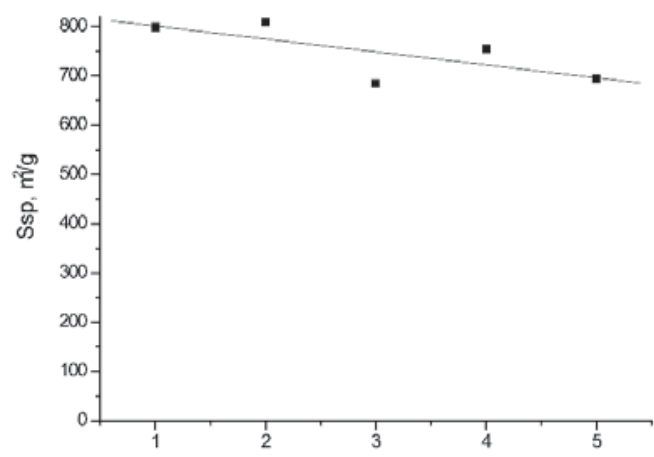

Fig. 7. Variation of the specific surface of sample $\mathrm{BAU}-\mathrm{A}$ ox. $\mathrm{Cu}^{2+}$ per cycles. 
In order to determine the influence of catalytic oxidation process with sulfides aeration the blind test was performed, i.e. the same oxidation procedure was repeated with aerated water containing no sulfides. Activated carbon used in this experience was dried to constant mass and subjected to adsorption investigations with the Autosorb 1MP.

Each cycle lasted 1 hour, after which hydrogen sulfide concentration decreased from $10 \mathrm{mg} / 1$ to $0 \mathrm{mg} / \mathrm{l}$. The $\mathrm{OH}^{\bullet}$ radical which is formed at the interface oxidizes some substance, possibly heavy hydrocarbons in activated carbon BAU structure and amorphous carbon remained after its obtaining process. Bubbling oxygen through the system comprising activated carbon BAU-A $+\mathrm{Cu}^{2+}$ in demineralized water for 1 hour (blank sample) with subsequent determination of the structure parameters of the catalyst, can be explained if the radical $\mathrm{OH}^{\bullet}$ can oxidize (remove) from the porous structure heavy hydrocarbons, left over from industrial process for obtaining activated carbon BAU.

\section{Conclusions}

1. As a result of oxygen bubbling through the water from the fountain in Hancesti containing hydrogen sulfide, sulfur is deposited in the porous structure of studied activated carbons, which decreases its catalytic activity, but the adsorption / oxidation of hydrogen sulfide to sulfate is also produced.

2. Kinetics of hydrogen sulfide removal from water of Hancesti after treatment with hydrogen peroxide demonstrates greater efficiency compared with the use of modified carbonic adsorbents, and as a result hydrogen sulfide is oxidized to sulfate.

\section{References}

[1]. Carroll, John L.. Discussion of the Effect of $\mathrm{pH}$ on the Solubility of Hydrogen Sulfide. Aqualibrium. 1998Publication Rights Reserved. P. 1-7.

[2]. Primavera, Alexandra; Trovarelli, Alexandro; Andreussi, Paolo; Dolcetti, Giuliano. The effect of water in the low temperature catalytic oxidation of hydrogen sulfide to sulfur over activated carbon. Applied Catalysis A General 173, 1998, 185-192.

[3]. Moosavi, G.R.; Naddafi, K.; Mesdaghinia, A.; Vaesi, F. and Mahmoudi, M. $\mathrm{H}_{2} \mathrm{~S}$ Removal in an Oxidative Packed Bed Scrubber Using Different Chemical Oxidants. Journal of Applied Sciences, 2005, 5 (4), 651- 654.

[4]. Feng, Wenguo; Kwon, Seokjoon; Borguet, Eric and Vidic, Radisav. Adsorption of Hydrogen Sulfide onto Activated Carbon Fibers: Effect of Pore Structure and Surface Chemistry. Environ. Sci. Technol. 2005, 39, 9744 - 9749.

[5]. Leuch, L.M. Le; Subrenat, A. and Le Cloirec, P. Hydrogen Sulfide Adsorption and Oxidation onto Activated Carbon Cloths: Applications to Odorous Gaseous Emission Treatments. Langmuir 2003, 19. 10869 - 10877.

[6]. Sayyadnejad, M.A.; Ghaffarian, H.R.; Saiedi, M. Removal of hydrogen sulfide by zinc oxide nanoparticles in drilling fluid. Int. J. Environ. Sci. Tehn. 2008, 5 (4), 565 - 569.

[7]. Bandosz, Tereza J. (Teaneck, NJ, US); Bahryeyev, Andriy (New York, NY,US); Locke, David C. (Brooklyn, NY,US). United States Patent Application 20110071022.

[8]. AUTOSORB AS-1. AS1Win. GAS SORPTION SYSTEM. OPERATION MANUAL. Firmware: ver 2.55. AS1Win Software: ver 2.0 and newer. Quantachrome Instruments, 2008.

[9] E.V.Basiuk, V.A.Basiuk, J.G.Bañuelos, J.M.Saniger-Blesa,V.A.Pokrovskiy, T.Y.Gromovoy, A.V.Mischanchuk, and B.G. Mischanchuk. Interaction of Oxidized Single-Walled Carbon Nanotubes with Vaporous Aliphatic Amines Chem. B v106, pp1588-1597 (2002).) 